\title{
Small organic farm renewable energy demonstration project based on incremental capital investment and community participation
}

\author{
Anna E. Demeo, a,b* College of the Atlantic \\ Michael L. Peterson, ${ }^{b}$ University of Maine
}

Submitted March 4, 2013 / Revised May 4 and June 29, 2013 / Accepted July 1, 2013 /

Published online November 14, 2013

Citation: Demeo, A. E., \& Peterson, M. L. (2013). Small organic farm renewable energy demonstration project based on incremental capital investment and community participation. Journal of Agriculture, Food Systems, and Community Development, 4(1), 141-154. http://dx.doi.org/10.5304/jafscd.2013.041.002

Copyright (C) 2013 by New Leaf Associates, Inc.

\begin{abstract}
Rising fuel prices, energy security, and climatechange awareness are all incentives for farmers to implement efficiency measures and renewable energy systems, such that all or part of a farm's energy needs are produced locally. This practice, known as clean energy farming, complements principles of sustainable agriculture such as promoting environmental stewardship, reducing dependence on nonrenewable resources, increasing economic viability, and strengthening farm families and society as a whole.

Farmers who entertain moving toward a more sustainable energy portfolio are often unsure where to begin and how to approach such an endeavor.
\end{abstract}

\footnotetext{
a College of the Atlantic, 105 Eden Street; Bar Harbor, Maine 04609 USA.

b Department of Mechanical Engineering, University of Maine, 5711 Boardman Hall, Room 219; Orono, Maine 04469 USA.

* Corresponding author: Anna Demeo, 105 Eden Street, Bar Harbor, Maine 04609 USA; +1-207-288-5015; ademeo@,coa.edu
}

This uncertainty, combined with the perceived enormity of the task, create an insurmountable roadblock for many. Overcoming these barriers and engaging in small-scale renewable energy projects can benefit the farmer and the larger community. Exposure to such projects is an invaluable means of fostering support for renewable energy as it helps the public better appreciate the human ecological connection between daily energy consumption, the source of that energy, and the overall effect on the environment.

The central objective of this paper is to demonstrate a model for sustainable energy for a working farm based on community participation and incremental capital investment. A small organic farm was used as the model to show how to migrate toward energy independence through efficiency and conservation measures, and the incorporation of technologies based on renewable resources. It is a portfolio approach, which allows for multiple technologies such as wind, solar, biomass, and efficiency measures to be implemented over time as funds become available. 


\section{Keywords}

clean energy farming, community, efficiency, renewable energy, sustainability

\section{Introduction}

Overwhelming scientific consensus exists that anthropogenic emissions of carbon dioxide and other greenhouse gasses will lead to significant and potentially catastrophic climate change in the next half-century (Intergovernmental Panel on Climate Change [IPCC], 2007). Reducing the use of fossil fuels and shifting toward a greater emphasis on renewable energy are the most urgent challenges in the effort to mitigate climate change (Walker, 1995). Agriculture worldwide is a significant contributor to the problem of climate change, accounting for up to 20 percent of total annual greenhouse gases. Emissions from agriculture are estimated at 6 gigatonnes $(\mathrm{Gt})$ of carbon dioxide equivalents $\left(\mathrm{CO}_{2} \mathrm{e}\right)$ and are expected to reach $8.3 \mathrm{Gt}$ $\mathrm{CO}_{2} \mathrm{e}$ per year by 2030 (Niggli, Schmid, \& Fliessbach, 2007). The food production system accounts for 17 percent of all fossil fuel use in the United States (Horrigan, Lawrence, \& Walker, 2002).

Sustainable farms have already made strides in reducing the carbon footprint of food production by limiting the use of fertilizers and pesticides and providing a local source of food to communities, which reduces emissions from food transportation (Weber \& Mathews, 2008). Implementing measures so that all or part of a farm's energy needs are produced sustainably and locally takes the concept of sustainability a step further. This practice, known as clean energy farming (Friedman, 2012), complements principles of sustainable agriculture such as promoting environmental stewardship, reducing dependence on nonrenewable resources, increasing economic viability, and strengthening farm families and society as a whole (Gerber, 1992). In recent years, the number of farms considering and implementing on-farm energy production systems has risen (Delhagen, 2008). The myriad of efficiency and renewable-energy efforts implemented on small farms across the country are often in conjunction with universities, extension programs, and nonprofit organizations that offer resources and information for farmers (Center for Ecological
Technology (CET), 2012; Center for Rural Affairs, 2012; Purdue Extension, 2009). One example is New York small farm energy innovators (Masler \& Bass, 2010), a compilation of energy efficiency and renewable energy projects on six New York farms.

In addition to issues of climate change and rising and unpredictable fuel prices are incentives for farmers to reduce energy costs from heat and electricity (Chel \& Kaushik, 2011). This is especially important for small farms, which allocate a greater proportion of their operating budget to purchased inputs such as energy (Thompson, 1986). While small farms make up only 10 percent of gross farm sales, almost seven in 10 of the 2.2 million farms in the U.S. can be classified as small (D’Souza \& Ikerd, 1996). This provides a significant opportunity for farms to play a vital role in shaping public opinion regarding energy conservation and the adoption of renewable sources of energy while strengthening their own resilience by transitioning away from fossil fuels.

A significant barrier to the widespread transition to renewable sources of power is the lack of public support for the adoption of renewable energy technologies (Stern, 2007). Despite obvious human, social, and cultural drivers of climate change, the link between fossil fuel production and consumption and global climate change is not well understood by the general public (Dwyer, 2011). According to Mulligan (2010), this is due to a lack of exposure to the fundamentals of energy on the practical side and an absence of the human ecological connection between man and nature on the conceptual side. Understanding issues of energy and climate in terms of human experiences will be needed to change energy use as well as to generate support for renewable energy development.

Arguably many small farms by their very existence already help educate the public about the connection between the food people eat and how and where that food is grown (Darnhofer, 2010). In the same way, moving toward a sustainable energy portfolio by engaging in small-scale renewable energy projects can serve to educate the larger community while also benefiting the farm economically and socially. Exposure to such projects is an invaluable means of fostering widespread understanding (National Environmental Education 
and Training Foundation \& RoperASW, 2002) as it helps the public better appreciate the human ecological connection between daily energy consumption, the source of that energy, and the overall effect on the environment (Mulligan, 2010).

While implementing efficiency and renewable energy projects can be an effective strategy for strengthening a farm and the surrounding community, the capital required and the perceived enormity of the task may deter farmers from engaging in such projects. Farmers who entertain moving toward a more sustainable energy portfolio are often unsure where to begin and how to approach such an endeavor. In addition, limited access to capital is often a barrier for small farms, making them slower to adopt technologies as compared to larger farms (Bieri, de Janvry, \& Schmitz, 1972). Therefore the central objective of this study is to demonstrate a model for integrating sustainable energy production into a working farm based on community participation and incremental capital investment.

A small, organic farm was used as the model to show how to migrate toward energy independence through efficiency, conservation, and the incorporation of renewable resources. It is a portfolio approach, which allows for multiple technologies, with different cost and benefit profiles, to be implemented over time as funds become available. This strategy of incremental capital investment requires a modest initial investment with the ability to realize the greatest gain at the early stages of the multistage project. By implementing efficiency measures and deploying technology over a period of time, farmers as well as businesses, organizations, and individuals can better afford to move to a more sustainable energy portfolio.

This paper details a renewable energy demonstration project on an organic farm. The three main pillars of the project are to (1) plan and follow through on a variety of conservation and renewable energy projects, (2) provide detailed financial and logistical information on each project, and (3) ensure energy education and community engagement through hands-on participation and ongoing outreach and dissemination of information.

\section{Overview}

The energy demonstration project was implemented at Beech Hill Farm and funded through a grant from Efficiency Maine Trust. Beech Hill farm is a 73 -acre (30-ha), small organic farm on Mount Desert Island on the coast of Maine. The farm has eight field units under tillage with a total of five acres ( $2 \mathrm{ha}$ ) of crop production. There are an additional 12 acres ( $4.9 \mathrm{ha}$ ) of open land that include two acres $(0.8 \mathrm{ha})$ of heirloom apples in three small orchards. The rest is forested land. The farm has many of the essential elements common to small vegetable producers: several acres of fields requiring pumped irrigation, commercial greenhouses that requires seasonal heating, a farmhouse, a multipurpose building for storage and office space, and a farm stand.

In addition to the strong financial and missiondriven incentives for small, sustainable farms to move away from the use of fossil fuels, there are numerous other reasons that a small farm is an ideal setting for this demonstration. First, farms have diverse energy needs and significant open space to model technologies such as solar and wind. Second, the solutions developed for a farmhouse are applicable to many residences, thereby making this useful to homeowners as well. And finally, the farm stand attracts customers who can then be exposed to the energy-saving and renewable energy innovations.

Beech Hill Farm is particularly well suited for community outreach both because it is owned by a college and is located in the same community as a national park. The college's sponsorship of workshops, class projects, student internships, and work-study positions provide exposure for the renewable energy demonstration project. The farm is a member of the Maine Organic Farmers and Growers Association (MOFGA) and is operated under an "open-book" policy, allowing other farmers to learn from the financial experience and alternative production techniques of the farm. Additionally the farm has a tradition of providing tours to visitors and groups from local schools and summer camps. A natural audience exists for the messages from the farm since it is located in the same community as Acadia National Park, which attracts 2.5 million visitors each year (Trotter, 
2011). This provides a broad and diverse spectrum of people to the farm stand, which itself draws over 15,000 visits per season.

\section{Process}

The initial phase of the project was to inventory energy consumption on the farm and gain a thorough understanding of the energy-dependent systems throughout the year. First, we collected baseline data to determine the total energy consumption on the farm, which was 54.4 megawatt hours (MWh) per year for heating and electricity. Four separate electricity meters and three separate fuel bills provided the relative difference in energy use between the many farm systems. Figure 1 details energy use by sector at the farm. Second, we documented procedures and growing cycles to gain an understanding of the farm's operations and each one's associated energy demands. Finally, we documented shortcomings of farm infrastructure and procedures as understood by the farmers.

Findings from this initial research provided a host of valuable information. Energy data confirmed high heating demands for the farmhouse and the greenhouses. Additionally the data showed that the water-pumping system was responsible for a large percentage of electricity use at the farm. This data aligned with what was learned about farm operations as shown in Table 1.

A systematic approach was taken to determine the most suitable strategy for implementing efficiency measures and renewable energy production at the farm. The approach selected one aspect of each of the major energy consumers on the farm: irrigation, greenhouse heating, and the farmhouse.

\section{Figure 1. Farm Energy Use by Sector}

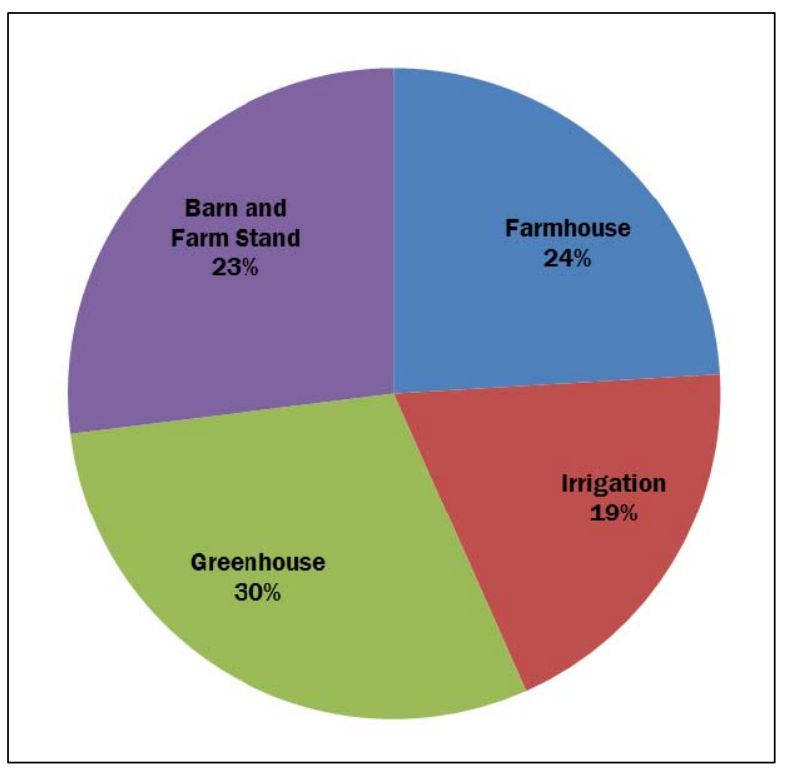

Demonstration of energy efficiency and non-fossil fuel based energy production was a key goal of this project. Therefore, we initiated projects for each of the major farm systems. Decisions on which efforts to invest in depended on three criteria: availability of funds, projected return on the investment, and demonstration potential for other farmers and the community.

\section{Renewable Energy Installations}

\section{Solar Photovoltaic}

As on many small produce farms, well pumps for the water used for irrigation and processing vegetables account for a substantial proportion of the farm's electricity. The farm has four wells; two are

\section{Table 1. Farm System Information for Beech Hill Farm Energy Demonstration Project}

\begin{tabular}{|c|c|c|}
\hline System & Conditions & Issue \\
\hline \multirow[t]{2}{*}{ Greenhouse } & $\begin{array}{l}\text { An older glass greenhouse is heated starting in early February for seed } \\
\text { germination. }\end{array}$ & High heating demand \\
\hline & The largest greenhouse is heated from early April through mid-November & Fossil fuel heat \\
\hline \multirow[t]{2}{*}{ Irrigation } & Irrigation of the fields generally becomes routine in May. & High electricity \\
\hline & Produce is washed from May through October. & High electricity \\
\hline \multirow[t]{2}{*}{ Farmhouse } & Farmhouse basement is damp and unsuitable for storage due to mold issues. & Health and quality of life \\
\hline & $\begin{array}{l}\text { The farmhouse is drafty and cold. A portion is closed off in the winter because } \\
\text { of this. }\end{array}$ & Quality of life \\
\hline
\end{tabular}


used for irrigation, one for washing vegetables and general barn use, and one for the farmhouse. Each of the wells is on a separate electrical service, which allows easy analysis of individual use. The average total electricity consumption of the well pumps, averaged over three years, is $10.5 \mathrm{MWh}$ per year, which is approximately 60 percent of the total electricity consumption on the farm.

Several strategies were explored in considering this issue. One approach was to reduce the overall water needed by changing to drip irrigation, a more efficient irrigation system. This approach met with resistance as the farmers were uncomfortable with changing an irrigation system that has worked very well for the past 20 years. This is a realistic response that highlights the human ecological component to migrating to a more sustainable energy platform. Forcing substantial changes of habit often increases resistance to action and support for projects. Acknowledging that conservation and climate change cannot be the sole metric for adopting a new energy portfolio, a multiyear plan was established to address irrigation issues. This includes installing monitoring equipment to study watering patterns and consumption. The results will provide the farmers with a comprehensive review of the cost, labor, and ecological footprint of using drip irrigation rather than the existing system.

In the near term, solar photovoltaic panels were used to reduce electricity use from water pumping. Water pumping is one of the simplest and most appropriate uses for solar photovoltaic (Chel \& Kaulshik, 2011). The number of solar panels installed was based on available resources and with the possibility of future expansion. Fourteen 230W (Y1230-29B) solar panels were installed, each with a micro-inverter (M190). The micro-inverters allow for system expansion and individual panel adjustment for shading. This is a grid-tie system that falls under a simple net metering agreement with the local utility as regulated by the state of Maine. This is a standard agreement that allows the farm to store excess electricity as kilowatt credits for up to one year. This is advantageous for the farm because energy consumption is not evenly distributed throughout the year. The solar panels will produce power during the winter when the farm consumes very little energy. Credited energy can be used during the growing season when the farm will consume more energy than it produces.

\section{Solar Photovoltaic Cost and Payback Calculations}

The combination of the fourteen $230 \mathrm{~W}$ panels gives the farm a total installed peak capacity of 3.2 $\mathrm{kWatts}$. The panels are producing $4360 \mathrm{kWh}$ of energy and offsetting roughly 4,400 lbs. (1,996 kg.) of $\mathrm{CO}_{2} \mathrm{e}$ each year. This accounts for 41.5 percent of all of the electricity needed for farm water pumping, as shown in figure 2. The total cost of installing the solar systems was $\$ 19,487$, which gives an installation cost of $\$ 6.05$ per watt. This was on par with the average installation cost in the northeast at the time, which was $\$ 6.30$ per watt (Barbose, Darghouth, Wiser, \& Seel, 2011).

While installation costs are a good measure for whether a contractor provided fair pricing, the calculated payback of the system is what dictates whether a project will be economically feasible for a business owner or individual. In order to properly calculate payback, state and federal rebate and tax incentive programs must be taken into account. Rebates vary from state to state; in the state of Maine the rebate is US $\$ 500$ per $1000 \mathrm{kWh}$ estimated annual production with a maximum of US\$2,000 for residential and US\$4,000 for commercial (U.S. Department of Energy [U.S. DOE], 2012a). Based on these rules, this project qualified for a US $\$ 2,000$ state rebate. The federal rules provide a 30 percent tax credit (DOE, 2012a), which amount to US $\$ 5,846$. There are also federal rules that allow accelerated depreciation on tax returns for solar installations. However, because tax rates are not uniform and depreciation rules fluctuate, they have been left out of the payback calculation. Combining state and federal incentives, the total cost of the project is reduced to US $\$ 11,641$, Using the current cost of electricity, US $\$ 0.17 / \mathrm{kWh}$, the simple payback time on the system is 15.7 years. As solar panels hold a 25-year warranty and are reported to last up to 40 years in some instances (Black, 2009), this is a suitable return on investment for many. However, solar costs have declined rapidly in the past year and are now at an average installed cost of US $\$ 4.44$ per watt (Wesoff, 2011). The solar arrays at the farm would have a payback 
time of 10 years given the current pricing, which makes a project like this even more attractive.

\section{Biomass}

The farm has four greenhouses, two of which are heated. The smaller, older heated greenhouse needs significant structural investment and is estimated to use at least as much energy as the larger, newer heated greenhouse. We launched a longer-term analysis of energy issues pertaining to the smaller greenhouse. Data gathered will be utilized for future improvements and/or a reduction in the heated use of that greenhouse. Therefore efforts for this work were focused on the newer, heated greenhouse. It is the largest greenhouse (Nor'easter, Rimol) and is used from early April through the middle of November. Heating requirements for the greenhouse are to maintain it to $60^{\circ} \mathrm{F}\left(16^{\circ} \mathrm{C}\right)$ from April 7 to May 15 for tomatoes, and at $38^{\circ} \mathrm{F}$ $\left(3^{\circ} \mathrm{C}\right)$ throughout March, October, and the first half of November for crops like carrots and greens.

Several options were considered as a renewable source of heat for the greenhouse, including a heat pump, cord-wood boiler, and pellet hot-air furnace. The cord-wood boiler was closely considered because the farm includes of over 65 acres (26 ha) of woodland. In addition to the higher cost, the added labor involved in harvesting wood, starting and feeding the boiler, and cleaning it more frequently was not realistic for the farmers given their extensive workload and unpredictable and often insufficient work force.

Ultimately a wood pellet heating system was selected and installed to replace the propane system as the primary source of supplemental heat in the greenhouse. This offset 10,000 lbs. $\left(4,536 \mathrm{~kg}\right.$.) of $\mathrm{CO}_{2} \mathrm{e}$ each year. The system cost US $\$ 5,800$ and consists of a pellet furnace (RH360), which is automatically fed pellets from a $600 \mathrm{lb}$. (272 kg.) storage pellet bin, known as the hopper (Mini, Mafa) through a $5.6 \mathrm{ft} .(1.7 \mathrm{~m}$.) augur (Pellx 20kW). The pellet heating system represents a modest increase in labor for the farmers compared to the propane system, as they periodically need to refill the hopper, empty the ash draw, and clean the furnace.

\section{Biomass Costs and Payback}

The amount of heat needed for the larger greenhouse was calculated to be $31,000,000$ BTUs (31 MMBTU) for the season based on the average nighttime temperatures, required inside temperatures for spring and fall, and the make and model of the greenhouse. Wood pellets provide 320,000 Btus per bag. They are purchased by the ton (fifty $40 \mathrm{lb}$. [18.1 kg.] bags), at a cost of US $\$ 245$ per ton (907 kg.) (U.S. Energy Information Administration [EIA], 2012). Therefore the pellet furnace, which has an efficiency of 85 percent, will burn 2.3 tons $(2,087 \mathrm{~kg}$.) of pellets in a season at a cost of US $\$ 564$. Propane provides 91,300 Btus per gallon. Using the three-year average price for propane of US $\$ 2.83 /$ gal. (U.S. EIA, 2012), an 85 percent efficient propane system will burn 404 gallons $(1,529$ liters) of propane, equivalent to $10,810 \mathrm{kWh}$, in a season at a cost of US $\$ 1,143$. Given the difference in heating costs, the pellet furnace has a simple payback time of 10 years. Figure 2 illustrates the
Figure 2. Irrigation and Greenhouse Energy Demand and Production

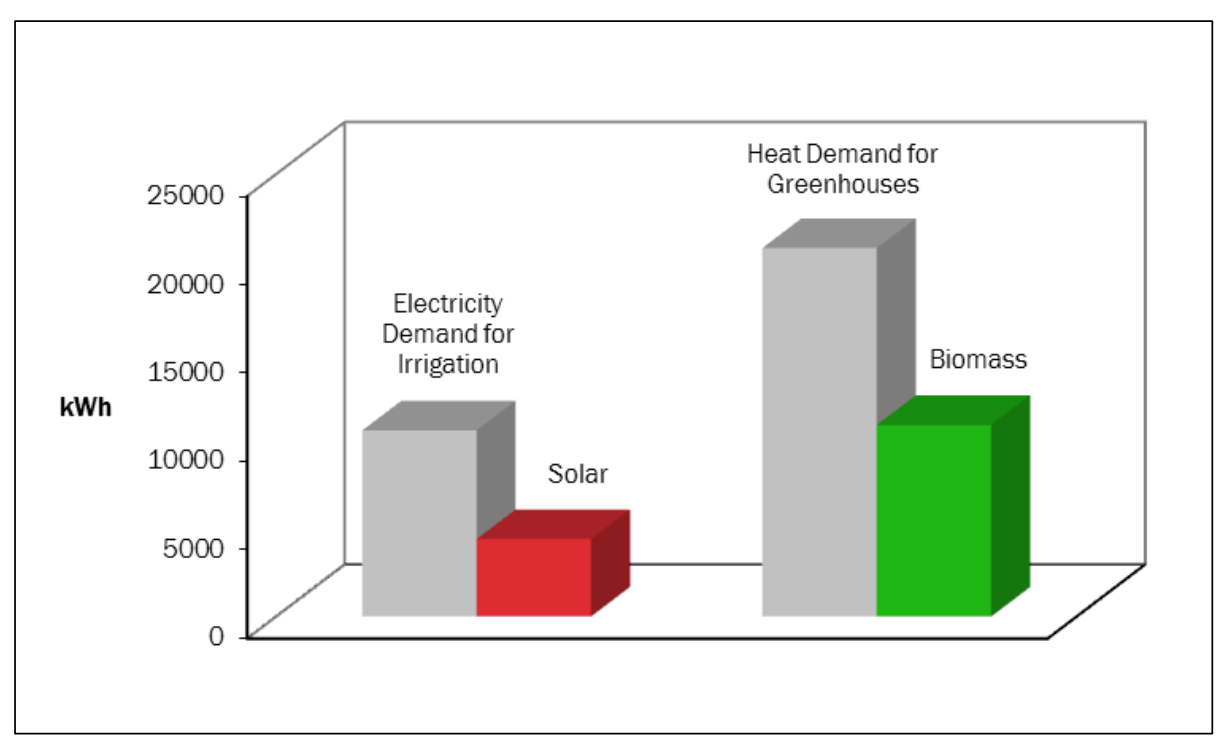


energy demand for total greenhouse heating and for electricity for irrigation with the associated renewable energy production.

\section{Heat Pump}

Demonstrating a lower carbon and low cost heat source for the farmhouse was of particular importance due to the location of the project. More than 80 percent of Maine households rely on oil for heat, the largest percentage of any state in the United States (U.S. EIA, 2012). The farmhouse was heated by a wood stove and a propane wallmount heater (RHFE-559FTA). We investigated heat pump technology as it conformed to Maine's Climate Future report (Demeo, Peterson, \& Rubin, 2009). The report proposed that heat pumps in conjunction with wood stoves are the optimum heating configuration for homeowners since they work most efficiently in moderate temperatures, while wood burns most efficiently in the coldest temperatures.

A mini-split air-source heat pump (12RLS2) was installed as part of a community workshop in which participants learned about heat-pump technology and then assisted in the installation of the system. This heat pump is rated to perform down to $-5^{\circ} \mathrm{F}\left(-21^{\circ} \mathrm{C}\right)$ and has an efficiency of 300 percent (DOE, 2012b). The heat pump replaced the existing propane heater, but the wood stove remains the primary heat source.

\section{Heat Pump Cost and Payback}

Supplemental heat to the wood stove in the farmhouse consisted of 200 gallons (757 liters) of propane. The propane heater has an efficiency of 85 percent; therefore it provided 15,521,000 total Btus or $4,549 \mathrm{kWh}$ of heat each year. The heat pump has an estimated electricity load of 1,173 kWh per year, which results in a net reduction of 3,377 lbs. (1,532 kg.) of $\mathrm{CO}_{2} \mathrm{e}$ per year. Given US $\$ 2.83$ per gallon for the cost of propane and US $\$ 0.17$ per $\mathrm{kWh}$ for electricity, the savings amount to US $\$ 367$ per year. The heat pump cost US $\$ 3,350$ (installed), and therefore the payback on the system is nine years. This is considered a relatively long payback for the heat pump due to the fact that the primary source of heat for the farmhouse is the wood stove rather than a fossil fuel source. The manufacturer payback of two to three years is reasonable for homes that use propane or oil as the primary heat source.

\section{Wind Turbine}

A wind turbine (Skystream 3.7) was installed as part of a college course prior to the start of the renewable energy demonstration project. The installation was the centerpiece of the course "A Practicum in Wind Power" offered in 2009 by the College of the Atlantic. Funding for the course and the turbine came from a combination of donors and a grant from the U.S. Environmental Protection Agency (U.S. EPA). The location of the turbine was chosen based on proximity to the farmhouse, available open space not needed for crops, and visibility to the community. The local ordinance for the town imposed a 40' height limit on the turbine.

\section{Wind Turbine Cost and Payback}

The height restriction, in addition to the other citing considerations, resulted in poor energy production for the turbine. In addition to the course itself being a good learning experience, however, the knowledge gained by the community as to the need for proper planning and good ordinances to produce wind power was invaluable. For example, if a taller tower had been permitted, in theory the turbine would be capable of producing almost three times as much energy per month, which would have reduced the payback time on the investment by nearly 20 years.

The students in the wind turbine course gave a presentation to the town planning board as the town worked to develop a wind power ordinance. The project and the presentation spurred extensive conversation about the role residential wind power could have for the wider community and how that would compare, from both aesthetic and energy generation perspectives, with larger, industrial-scale turbines.

In terms of the energy demonstration project for the farm, cost and installation information about the wind turbine is very instructive. The total installation cost of the project was roughly US $\$ 18,000$. State and federal tax incentives and rebates on a project of this size amount to 
US $\$ 7,400$, bringing the total cost of the project to US $\$ 10,600$. The total average yearly energy production for the turbine is $2223 \mathrm{kWh}$, or about half of the farmhouse electricity load. This translates to US $\$ 378$ savings in electricity costs and 2,224 lbs. $\left(1,009 \mathrm{~kg}\right.$.) of $\mathrm{CO}_{2} \mathrm{e}$ per year. At that rate, the wind turbine will pay for itself in 31 years, which is beyond the lifespan of the turbine.

\section{Efficiency Measures}

The farmhouse is a significant aspect of this project even though its energy consumption is a small proportion of the overall energy use of the farm. This is because the improved quality of life and reduction in residential energy use is not only relevant to farmers but to individual homeowners as well. The farmhouse is a one-story, 1,600 square foot (149 square meter) contemporary, twobedroom house with a full basement. The farmers close off the back living space through the winter since the heating system is inadequate to maintain a comfortable temperature for the entire house.

The basement can be accessed via interior stairs or through a deteriorated external bulkhead and its unsafe stairway. The basement has a dirt floor and extended 10' 8" (3.2 m.) concrete walls. Excessive moisture is present in the basement due to foundation mortar deterioration. There is extensive mold on the exposed fiberglass insulation in the floor joists and evidence of flooding. With the exception of a washer and dryer located on a raised platform at the bottom of the interior stairs, the basement is unusable.

\section{Energy Audit}

While understanding the electricity for irrigation and propane for heating the greenhouses is fairly straightforward, understanding the complexities of the energy use at the farmhouse required a professional energy audit. The audit was commissioned as the first expenditure for addressing the farmhouse.

The energy audit indicated that the farmhouse had an air exchange rate per hour of 0.7 ; the target is 0.35 for an energy-efficient house. This means that the building is 100 percent overventilated, or "leakier," than energy-efficiency standards. Annual energy use for the house consists of heating (67 percent of total usage), domestic hot water (16 per- cent), and appliances and lights (17 percent). The audit found that 55 percent of heat is lost through infiltration, while 24 percent is due to surfaces and doors and 17 percent due to windows.

The total estimated cost to complete all improvements to the house to make it highly energy efficient is US\$60,000. Implementing the improvements all at once was not a fiscally viable or desirable approach. Rather, we put into place an incremental approach to improving the energy efficiency of the farmhouse. Decisions about which items to take action on in the near term were based on available funds and health and quality-of-life concerns for the farmers. Concentrating primarily on the basement served to make the largest impact on the energy loss in the house while also addressing air-quality and safety concerns for the residents. Increased storage space in the basement is an additional value to this approach.

\section{Insulation and Air Sealing}

Insulation is a critical component of energy efficiency. The EPA estimates that homeowners can typically save up to 20 percent of heating by airsealing their homes and adding insulation (Energy Star, n.d.). The perimeter of the upper basement walls was insulated with 3 " $(7.6 \mathrm{~cm}$.) thick closedcell spray foam R21 insulation. Insulating the perimeter of the basement allowed for the removal of the moldy fiberglass insulation in the ceiling bays. The basement was further sealed with the installation of a 15-mil. vapor barrier over the dirt floor of the basement. This sealed barrier served to reduce moisture and heat loss. Window sashes were replaced with 2" $(5 \mathrm{~cm}$.) foam board inserts. The existing exterior bulkhead structure, stairs leading down to the basement, and interior door at the bottom of the bulkhead stairs were all replaced. Two-inch $(5 \mathrm{~cm}$.) polystyrene foam board was used to insulate the exterior walls of the basement.

Insulation and Air Sealing Costs and Payback

The total cost of this work was US\$8,082. Actual savings cannot be determined for some time, but overall payback for the improvements was estimated in the energy audit to be about 16 years. Carbon dioxide reductions due to this work is estimated to be 1,000 lb. (454 kg.) per year. Some 
of the improvements, such as the vapor barrier, did not include a financial savings estimate as the vapor barrier will not perceptibly lower the heating needs of the building. It will improve air quality and aid in protecting the longevity of all insulation improvements. Three important benefits beyond financial savings include improved comfort of the house, increased value of the building, and ability to utilize the large basement space for storage. Figure 3 details the proportional impacts of energy efficiency and renewable power production for the farmhouse.

\section{Outreach}

Beyond moving an organic farm toward fossil fuel independence, a wider reaching goal of this project is to engage the community so that community members can both participate in the work and utilize the results in a beneficial manner. Research shows that the ability to disseminate information into a community can promote not just individual benefits but also add to the overall strength of a community (Flora \& Flora, 1993). We held seven workshops in all, attended by anywhere from five to 20 people. Students, community members, business owners, and other farmers all had the opportunity to participate. Participants learned about the particular energy issue being addressed and why and how the given solution was chosen. Then they

Figure 3. Farmhouse Wind Turbine Energy Profile

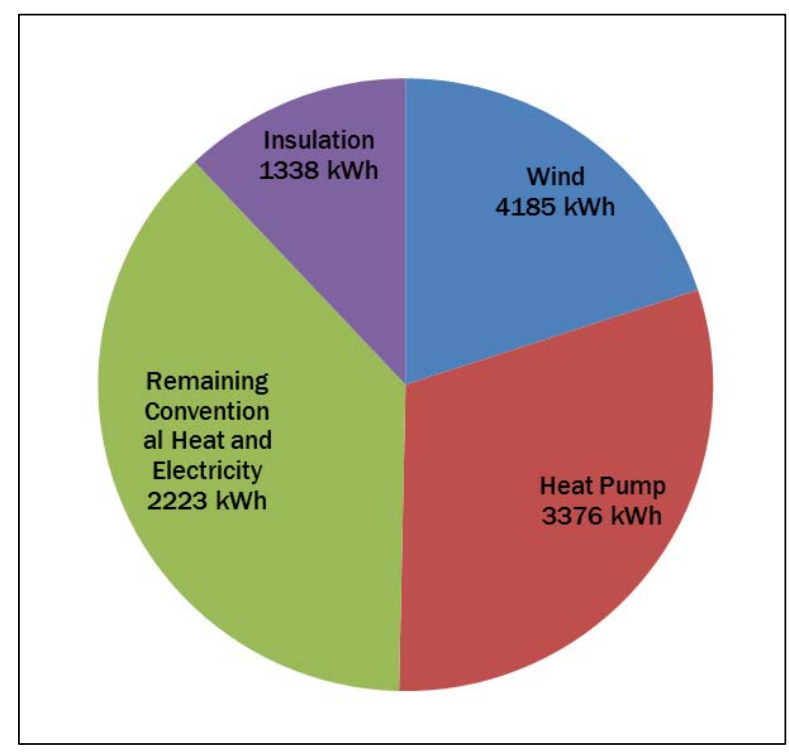

were taught about the specific technology and went on to help in the installation process.

For example, two separate photovoltaic arrays were installed, one roof mount and one ground mount, as part of two separate workshops. Participants learned the difference between grid tie and off-grid systems, how to read the sun resource calibrator, and how to prepare the foundation and install the panels. Real-time and historical performance of the solar panels as well as updated cost information are provided through a website for the public to reference.

We interviewed workshop participants who took personal action as a result of their involvement in the energy project as a means of tracking community impact. We conducted the interviews in accordance with proper human subject procedures and approval. As an example, we interviewed a local mechanic about a solar array he installed for his business subsequent to participating in numerous outreach events. When interviewed the participant remarked that renewable energy had always been of interest to him, but he had assumed previously that solar was not cost-effective on the coast of Maine. He explained that being able to view live data from the farm's solar array and inspect the solar panels first-hand prompted him to pursue the subject further.

After looking at the cost of the solar arrays at the farm and learning about state and federal incentives that are available, he obtained a quote for a solar array installation on his 2,500 square foot (232 square meter) mechanic's garage. He consulted project team members and outreach material throughout the purchase and installation of 20 solar panels, totaling $4.6 \mathrm{~kW}$ of peak capacity. The business, located in a small town where the primary employment opportunities are boat building, fishing, and tourism, has created a ripple effect within the community. The owner has fielded questions about his solar array and directed people to resources for further information.

We also interviewed a homeowner who participated in both the roof-mount solar installation and the heat-pump workshop. He sought out the workshops with the intention of moving to a more sustainable energy source for his personal residence. In addition to participating in the workshops, he 
Table 2. Cost and Payback for Demonstration Project Measures

\begin{tabular}{lcccl}
\hline Technology & $\begin{array}{c}\text { Cost } \\
\text { (all in US } \$)\end{array}$ & $\begin{array}{c}\text { Energy } \\
\text { Produced/Saved } \\
(\mathbf{k W h} / \text { year })\end{array}$ & $\begin{array}{c}\text { Payback } \\
\text { Period } \\
\text { (Years) }\end{array}$ & Notes \\
\hline Solar & $\$ 11,641$ & $+4,360$ & 15.7 & $\begin{array}{l}\text { Falling solar costs reduce a project of this size to } \\
\text { US } \$ 7,856 \text { with a 10-year payback. }\end{array}$ \\
\hline Biomass & $\$ 5,800$ & $+10,800$ & 10 & Payback based on propane replacement. \\
\hline Heat Pump & $\$ 3,350$ & $-3,376$ & 9 & $\begin{array}{l}\text { Payback 2-3 years for average home heating use } \\
\text { in Maine (U.S. DOE, 2012b). }\end{array}$ \\
\hline Wind & $\$ 18,000$ & $+2,223$ & 31 & $\begin{array}{l}\text { A turbine mounted on a taller tower would perform } \\
\text { better. }\end{array}$ \\
\hline Energy Audit & $\$ 500$ & NA & NA & $\begin{array}{l}\text { Maine offers stipends for insulation work if a } \\
\text { professional energy audit is completed first. }\end{array}$ \\
\hline $\begin{array}{l}\text { Insulation and } \\
\text { Efficiency }\end{array}$ & $\$ 8,082$ & $-1,370$ & 16 & $\begin{array}{l}\text { Energy saved and payback are estimates based on } \\
\text { findings from the energy audit. }\end{array}$ \\
\hline
\end{tabular}

took part in a farm tour during an open-house event and utilized the web resources for the project. In a follow-up interview about the project he explained that he had been leaning toward installing a wind turbine at his home. However, after discussing permitting requirements for wind turbines with students and other team members and looking at the energy production of the farm's wind turbine, he began to explore solar panels instead. By monitoring online the energy production of the farm solar panels he found the optimum array size for his house. Learning the basics about solar energy during the workshop, especially the importance of the optimum angle and position of the solar panels, gave this homeowner confidence to invest in solar energy. He is currently working with a local solar distributor to determine the total cost for a home system.

In addition to solar panels, the homeowner is actively pursuing installing an air-source heat pump in his home. The heat pump workshop he attended began with a PowerPoint presentation describing heat pump technology and how it can be best used. In the interview, the homeowner explained that he had just superficial knowledge of heat pumps prior to the workshop and was impressed with the efficiency of the technology. Upon further investigation he found that the initial cost and relatively short pay-back period made the investment worthwhile to him.

A number of methods were utilized to ensure that information about the project continued to be disseminated to the wider community. An annual "May Day" celebration was started to draw attention to the energy efforts at the farm. The inaugural event brought in over 100 people and included tours of the renewable energy projects. Additionally, a website was developed containing all of the information about the project, including manufacturers, cost analysis, a video, and links to real-time energy production of the solar panels and wind turbine. ${ }^{1}$ We also developed a comprehensive brochure and sent it to the local chamber of commerce, MOFGA members and made it available at the farm stand and online. The farm stand also has a large poster that describes the overall project and enables interested people to take a self-guided tour of the project.

\section{Discussion}

The goal of this work is to demonstrate a strategy for small farms as well as homeowners and small businesses to move to a more sustainable energy portfolio. The strategy is based on an incremental capital investment approach that allows improvements in efficiency and renewable energy projects to be implemented over time as funds become available. This paper details the first round of efforts, any one of which could be a first step for a farm, business, or homeowner. In all, US $\$ 47,000$ was spent on energy-related work at the farm during this demonstration project. Table 2 details the

\footnotetext{
${ }^{1}$ http://www.coa.edu/energy
} 
costs and estimated paybacks of each project.

Taking into account efficiency measures, the heat pump, and projected greenhouse heating, the net total heat and electricity consumption of the farm going forward is $37,800 \mathrm{kWh} /$ year. Total renewable energy production on the farm, including solar, wind, and biomass account for nearly $22,200 \mathrm{kWh}$, or 59 percent of the total energy consumption. The greenhouse gas emissions saved from the culmination of this project are 21,300 lbs. (9,662 kg.) of $\mathrm{CO}_{2} \mathrm{e} /$ year.

Although the economic gains from the work will accumulate over time, the outreach and educational values are more immediately evident. Utilizing an incremental approach to migrating to a sustainable energy is beneficial from an educational standpoint as well as an economic one. The renewable-energy project funded internships for college students that allowed them to play a central role in facilitating every aspect of the work. One of the first interns to work on the project describes the internship in a follow-up interview as her first opportunity to work with professionals in the field on a "real" project. Her responsibilities included communicating with vendors to get pricing information, helping to analyze data, and organizing workshops and other related events. The student explained that the experience taught her valuable lessons in communication, creativity, and project-

Figure 1. Farm Present and Future Energy Demand and Production

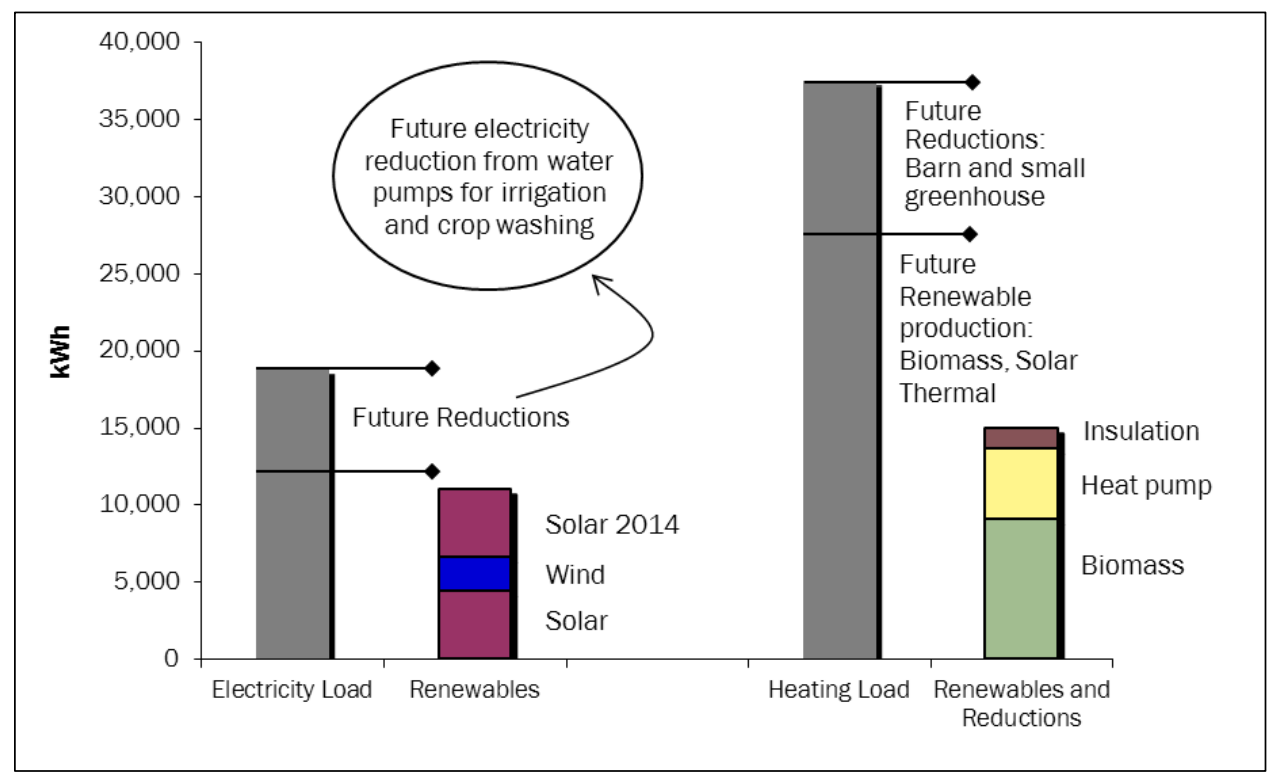

management skills. She had a chance to use her coursework in a hands-on, real-world setting. She noted that the experience taught her how to get things done, which has proved a valuable skill in many of her endeavors since. In addition to going on to be a teaching assistant for both a solar course and a sustainable-energy course at the college, the student proceeded to work on several renewable energy projects within the community and beyond. She dedicated a full term to working within the green business department of the college to further a private-public partnership focused on renewable energy projects for nonprofit organizations. The following summer she completed an internship as a project manager for a solar installation for a local business.

The college is known for its hands-on educational philosophy, and the farm is instrumental in providing real-world experience in farming, science, and now, through this work, energy. Building on the success of the energy demonstration project, and striving to incorporate a growing student interest in real-life, hands-on energy projects, the farm energy work has been incorporated organically into coursework at the college. Over the next three years more energy projects will be implemented through student coursework, internships, and workshop participation, with the goal of making the farm free of fossil fuels. Projects based on

data collected as a result of this work will include reducing energy from water pumping for irrigation and vegetable processing, reducing or eliminating heating in the oldest greenhouse, incorporating more solar energy, and utilizing pumped storage. Figure 4 shows the breakdown of renewable energy and efficiency measures, present and future, in relation to heating 
and electricity loads.

Rather than simply hiring professionals to do this work, an incremental approach over time allows a multitude of students to gain real experience. In the spring 2013 term offering of "The Math and Physics of Sustainable Energy" course, students performed a term-long investigation of irrigation and water issues at the farm and presented their findings and recommendations to the college administration and area farmers. The fall 2013 "Practicum in Renewable Energy" course will focus exclusively on implementing some of their recommendations as well as laying the groundwork for other components of the farm energy work. With this structure, each new student group or class will have the opportunity to install or implement a shovel-ready task and then investigate and analyze a new topic and lay the groundwork for the next group to implement. Such a format allows students to participate in different stages of project management as well as gain insight into more than one type of project.

\section{Conclusions}

The purpose of this project was to demonstrate a variety of conservation and renewable energy measures while transitioning a local organic farm to a sustainable energy portfolio. By implementing and documenting a range of strategies, others are able to have first-hand exposure on how to go about approaching energy-related projects and therefore better plan for making similar investments on an incremental basis. The farm's location and academic affiliation were paramount in effectively reaching a significant number of people with relatively modest resources. The location of the farm and open-book policy enables seasonal tourists and year-round residents to take tours as well as have full access to online data and vendor information.

Rarely is there a one-size-fits-all approach for projects of this nature, and this demonstration is no exception. There are numerous challenges for those who seek to replicate this approach. Each property is unique, with its own set of advantages, disadvantages, needs, and constraints. Determining in which order to approach projects can be timeconsuming, as cost and paybacks need to be calcu- lated and weighed against other factors, such as initial capital required and the potential increase in quality of life. An energy auditor can help with this, but that expense will not have an immediate return.

Another challenge is navigating federal and state tax incentives, rebates, and loan programs, which make these projects viable but can be confusing. This is compounded by the fact that the programs and rules can change every few years. Vendors and installers can assist with some of the paperwork involved in recovering state and federal funds, and knowledgeable accountants can help with tax and depreciation incentives.

The energy demonstration project at Beech Hill farm benefited greatly from the close relationship with an academic institution in that the college provided resources, a work force, and knowledge. Given fewer resources, some farms will require a longer time line to accomplish goals of energy sustainability. However, the approach detailed here remains relevant. Gathering baseline data to understand where and how energy is consumed is an essential first step for any sustainable energy project. Determining where to allocate limited resources will always be challenging, but realizing that each endeavor can be thought of in terms of cost, benefits, consequences, and paybacks is a useful frame from which to view options. Finally, implementing projects one system at time, as funds become available, alleviates some of the financial pressure while at that same time providing a clear path forward.

Building on this work, beyond making Beech Hill Farm free of fossil fuels, is to investigate the potential for farmers, small business owners, and individuals to work together, leverage larger purchasing power, and thereby reduce costs. Also of interest is to examine the way in which nonprofit organizations can partner with for-profit entities so that they may benefit from state and federal subsidies. Both of these endeavors build on the basic goal of this project, which was to move toward a more sustainable energy portfolio in a way that is economically viable and offers benefits to the business, the community, and the environment. From a societal perspective, fostering similar projects through public participation, outreach, and education strengthens support for larger renewable 
energy projects and helps the public make the human ecological connection between energyconsumption habits and the environment.

\section{Acknowledgements}

The State of Maine Public Utilities Commission provided funding for the Beech Hill Farm renewable energy project through its community development projects renewable resources fund (RFP 201004690). Special thanks to Robert Parker, who was instrumental in the creation and implementation of this work. Over the course of the project we have benefited from discussion, advice, and support from College of the Atlantic students and Beech Hill Farm managers and employees Andy Griffiths, Tom Adelman, Jenel Therlow, Curry Cuputo, Adam Barker-Hoyt, John Horton, Gary Gould, Dave Feldman, Craig Ten Broeck, Siegmar Eschholz, and Jay Friedlander.

\section{References}

Barbose, G., Darghouth, N., Wiser, R., \& Seel, J. (2011). Tracking the sun $I V:$ An historical summary of the installed cost of photovoltaics in the United States from 1998 to 2010 (Report LBNL-5047E). U.S. Department of Energy, Environmental Energy Technologies Division, Lawrence Berkeley National Laboratory. Retrieved from the Lawrence Berkeley National Laboratory website: http://eetd.lbl.gov/

Bieri, J., de Janvry, A., \& Schmitz, A. (1972). Agricultural technology and the distribution of welfare gains. American Journal of Agricultural Economics, 54(5), 801-808. http://dx.doi.org/10.2307/1239220

Black, A. (2009). Economics of solar electric systems for consumers: Payback and other financial tests. San Jose, California: OnGrid Solar. Retrieved from http://www.ongrid.net/papers/PaybackOnSolar SERG.pdf

Center for Ecological Technology (CET). (2012). CET Online: Energy \& small farm sustainability. Retrieved from http://198.170.83.99/FarmBusiness/ farm_energyOverview.htm

Center for Rural Affairs. (2012). Energy resources. Retrieved from http://www.cfra.org/EnergyResources/mainpage
Chel, A., \& Kaushik, G. (2011). Renewable energy for sustainable agriculture. Agronomy for Sustainable Development, 31(1), 91-118. http://dx.doi.org/10.1051/agro/2010029

Darnhofer, I. (2010). Strategies of family farms to strengthen their resilience. Environmental Policy and Governance, 20(4), 212-222. http://dx.doi.org/10.1002/eet.547

Delhagen, E. (2008). Farm energy innovation in Vermont: A report to the Vermont Sustainable Agriculture Council. Randolph, Vermont: Verdana Ventures LLC: Retrieved from http://www.uvm.edu/sustainable agriculture/Documents/energy innovation.pdf

Demeo, A., Peterson, M., \& Rubin, J. (2009). Energy. In G. L. Jacobson, I. J. Fernandez, P. A. Mayewski, \& C. V. Schmitt (Eds.), Maine's climate future: An initial assessment (pp. 56-59). Orono, Maine: University of Maine. Retrieved from http://climatechange. umaine.edu/files/Maines Climate Future.pdf

D’Souza, G., \& Ikerd, J. (1996). Small farms and sustainable development: Is small more sustainable?. Journal of Agricultural and Applied Economics, 28, 73-83.

Dwyer, C. (2011). The relationship between energy literacy and environmental sustainability. Low Carbon Economy, 2(3), 123-137. http://dx.doi.org/10.4236/lce.2011.23016

Energy Star (n.d.). Methodology for estimated energy savings from cost-effective air sealing and insulating. Retrieved from http://www.energystar.gov/index.cfm?c= home sealing.hm improvement methodology

Flora, C. B., \& Flora, J. L. (1993). Entrepreneurial social infrastructure: A necessary ingredient. Annals of American Academy of Political and Social Science, 529(1), 48-58.

http://dx.doi.org/10.1177/0002716293529001005

Friedman, D. (2012). Clean energy farming: Cutting costs, improving efficiencies, harnessing renewables [Bulletin]. Sustainable Agriculture Research \& Education [SARE]. Retrieved from http://www.sare.org/publications/energy.htm

Gerber, J. M. (1992). Farmer participation in research: A model for adaptive research and education.

American Journal of Alternative Agriculture, 7(3), 118-121. http://dx.doi.org/10.1017/S0889189300004628 
Horrigan, L., Lawrence, R. S., \& Walker, P. (2002). How sustainable agriculture can address the environmental and human health harms of industrial agriculture. Environmental Health Perspectives, 110(5), 445-456. http://dx.doi.org/10.1289/ehp.02110445

Intergovernmental Panel on Climate Change [IPCC]. (2007). Climate change 2007: The physical science basis. Contribution of working group I to the fourth assessment report of the intergovernmental panel on climate change. S. Solomon, D. Qin, M. Manning, Z. Chen, M. Marquis, K. B. Averyt,...H. L. Miller (Eds.). Cambridge, UK, and New York: Cambridge University Press.

Masler, A., \& Bass, A. (2010). New York farm energy innovators. Ithaca, New York: Cornell Small Farms Program. Retrieved from http://smallfarms.cornell.edu/

Mulligan, S. (2010). Energy, environment, and security: Critical links in a post-peak world. Global Environmental Politics, 10(4), 79-100. http://dx.doi.org/10.1162/GLEP_a_00032

National Environmental Education and Training Foundation [NEETF] \& RoperASW. (2002). Americans' low “energy IQ": A risk to our energy future. Washington, DC: NEETF.

Niggli, U., Schmid, H., \& Fliessbach, A. (2007). Organic farming and climate change (Document No. MDS-08152.E). Geneva, Switzerland: International Trace Centre.

Purdue Extension. (2009). Learn to convert on-farm resources into renewable energy at Farm Science Review. Retrieved from http://www.agriculture.purdue.edu/ AgAnswers/story.asp?storyID $=5526$
Stern, N. (2007). The economics of climate change: The Stern review. London: Cambridge University Press.

Thompson, E. (1986). Small is bountiful: The importance of small farms in America. Washington, D.C.: American Farmland Trust.

Trotter, B. (2011, February 7). 2.5M visited Acadia Park in 2010. Bangor Daily News. Retrieved from http://bangordailynews.com/2011/02/07/ outdoors /2-5m-visited-acadia-park-in-2010/

U.S. Department of Energy [DOE]. (2012a). Database of state incentives for renewables and efficiency: Maine incentives/policies for renewables \& efficiency. Retrieved from http://www.dsireusa.org/incentives/index. cfm?re $=0 \&$ ee $=0 \& s p v=0 \& s t=0 \& s r p=1 \&$ state $=\mathrm{ME}$

U.S. DOE. (2012b). Air-source heat pumps. Retrieved from http://energy.gov/energysaver/articles/air-sourceheat-pumps

U.S. Energy Information Administration [U.S. EIA]. (2012). Maine state profile and energy estimates. Retrieved from http://www.eia.gov/beta/state/?sid=me

Walker, G. (1995). Renewable energy and the public. Land Use Policy, 12(1), 49-59. http://dx.doi.org/10.1016/0264-8377(95)90074-C

Weber, C. L., \& Mathews, H. S. (2008). Food-miles and the relative climate impacts of food choices in the United States. Environmental Science \& Technology, 47(10), 3508-3513. http://dx.doi.org/10.1021/es/702969f

Wesoff, E. (2011). Solar power year in review 2011. GreenTechSolar. Retrieved from http://www.greentechmedia.com/articles/read/ $\underline{\text { Solar-Power-Year-in-Review-2011 }}$ 